\title{
A digital signal processor based capacitor inductor inductor resonant converter for stand alone wind energy system using $\mathrm{AC}$ analysis
}

\author{
${ }^{1}$ C. Nagarajan, ${ }^{2}$ R. Prakash \\ ${ }^{1,2}$ Centre for Advanced Research, Department of Electrical and Electronics Engineering, Muthayammal Engineering College, Salem, Tamilnadu, INDIA \\ E-mail: C. Nagarajan ${ }^{1}$ (nagaraj2k1 @ gmail.com_Corresponding Author) \\ ORCID iDs: https://orcid.org/0000-0002-5122-478X (Nagarajan), https://orcid.org/0000-0001-9102-2050 (Prakash)
}

\begin{abstract}
In this paper the CLL (capacitor inductor inductor) resonant converter (RC) with digital signal processor (DSP) based fuzzy controller for stand alone wind energy system has been estimated and the performance of the converter is analysed. The proposed converter has been analyses with the closed loop condition. The fuzzy controller regulates the output voltage with change of supply voltage and load disturbance are carried out. The controller performance of CLL RC is compared through simulation and experimental studies using TMS320F2407 processor.
\end{abstract}

Keywords: Power electronics, DC-DC power converters, fuzzy control, wind energy system

DOI: http://dx.doi.org/10.4314/ijest.v12i4.5

Cite this article as:

Nagarajan C., Prakash R. 2020. A digital signal processor based capacitor inductor inductor resonant converter for stand alone wind energy system using AC analysis. International Journal of Engineering, Science and Technology, Vol. 12, No. 4, pp. 54-63. doi: 10.4314/ijest.v12i4.5

Received: January 7, 2020; Accepted: October 8, 2020; Final acceptance in revised form: October 15, 2020

\section{Introduction}

Recently for medium and high power applications at high voltages, resonant converters have been found for realistic solution. The research in this field has been shown more interest by many researchers in developing the load independent converters using various concepts. They are gaining extensive popularity among their excellent performance like output voltage with negligible THD (Total Harmonics Distraction), reduced rippled and regulated de output voltage, reduced voltage stress and low EMI emission. It has been suggested to design Resonant Converter with three reactive components for better regulation. It has been found that these converters experience high switching losses, reduced reliability, Electro Magnetic Interference (EMI) and acoustic noise at high frequencies. Moreover, the series parallel resonant converters are found to perform better.

The design and development of various DC-DC Resonant Converters (RC) have been focused for telecommunication and aerospace applications in the recent past. It has been found that these converters experience high switching loss, reduced reliability, increased Electro Magnetic Interference (EMI) and high acoustic noise at high frequencies. The Converter in solid state devices is operated at very high frequency and hence the switching losses are expected to be more than the conduction losses. It becomes a major cause for poor efficiency of the converter circuit. This has led to the search of converter which can provide high efficiency, lower component stress, high power, high switching frequency, light weight as well as low cost and high power operation. Nowadays, resonant converters are widely used for switching power supplies, AC and DC motor drives and various applications. It is widely perceived as the best candidate for the next generation power converters. Among all the topologies of the resonant converters, the Series Parallel Resonant Converter (SPRC) shares the advantages of both the pure series converter and 
pure parallel converters. The LCL tank circuit based DC-DC Resonant Converter has been experimentally demonstrated and reported by many researchers (Bhat, 1994; Raju and Doradla, 1995; Borage et al., 2007).

Annamalai and Kumar (2010) have developed the CLL resonant converter for wind energy system. The simulation studies of the converter with open and closed loop system was presented. Borage et al. (2005) have demonstrated the characteristics of LCL-T Resonant converter using Asymmetrical duty cycle (ADC). The converter operated at fixed resonant frequency and its analysised using state space approach. Belaguli et al. (2000) have experimentally demonstrated with independent load when operated at resonant frequency, making it attractive for application as a constant voltage (CV) power supply. It has been found from the literature that the LCL tank circuit connected in series-parallel with the load and operated in above resonant frequency improves the load efficiency and independent operation. Mattavelli et al. (1997) have described the fuzzy logic control (FLC) for DC-DC converter. This control technique relies on the human capability to understand the system's behavior and is based on qualitative control rules. The FLC approach with same control rules can be applied to several dc-dc converters. However, some scale factors must be tuned according to converter topology and parameters. The author used the control technique for Buck-Boost converter and demonstrated. Correa et al. (2003) have demonstrated a DC/AC series resonant converter with fixed load considering fuzzy control approaches. Lakshminarasamma et al. (2011) have demonstrated active clamp Zero Voltage Switching (ZVS) DC-DC converter. The steady state stability analysis was presented for ZVS Buck converter. There is no possible of load independent operation. The converter operates at duty cycle $>0.5$, above its operation the converter fails to instability.

Arun and Raddy (2008) mentioned that the ZVS LCL push-pull Converter with closed loop operation was demonstrated using PI controller. Resonant Topology like LCL and LLC Resonant Converter are compared with open loop and closed loop. Here the load variation and load independent operation not presented, and there was no static and dynamic analysis. Later, Foster et al. (2008) have demonstrated CLL half bridge Resonant Converter with open loop operation. The ac equivalent circuit analysis and fundamental mode approximation (FMA) analysis was derived used to the modeling the converter and compared. The evaluation of static and dynamic performance was not provided. Later, Sivakumaran and Natarajan (2006) developed a CLC SPRC using FLC for load regulation and line regulation. The performance of controller has been evaluated and found that the load independent operation may not be possible. The FLC based ZVS quasi-resonant converter has been demonstrated (Arulselvi et al., 2006; Udhayakumar and Ponnus, 2008; Nagarajan and Madheswaran, 2011; Nagarajan and Madheswaran, 2011). The load independent operation was not realized and power handling capacity of the converter is found to be poor. A number of studies (Nagarajan and Madheswaran, 2007; Nagarajan and Madheswaran, 2011; Nagarajan et al., 2013; Lakshmi and Nagarajan, 2017; Geetha and Nagarajan, 2018; Daniel and Nagarajan, 2018) have simulated an LCL-T SPRC using FLC and PID controller. The performance of controller has been found to be better when the fuzzy controller has been considered. The harmonic spectrum and dynamic analysis for RLE load are presented.

It is clear from the above literatures that the output voltage regulation of the converter against load and supply voltage fluctuations have important role in designing high-density power supplies. The RC is expected to have the speed of response, voltage regulation and better load independent operation. Keep the above facts in view, the CLL RC has been modeled and analyzed for estimating various responses. The closed loop with fuzzy controller has been derived and simulated using MATLAB/Simulink. A prototype $300 \mathrm{~W}, 100 \mathrm{kHz}$ the $\mathrm{RC}$ is implemented and the experiment results are compared with the simulation results. The simulation results agree with the experimental results.

\section{Proposed CLL Resonant Converter for Stand Alone Wind Energy System}

The block diagram of RC is shown in Figure 1. The first stage converts the high frequency AC voltage to a DC voltage. The second stage is the DC power is given to the resonant circuit. The next stage is the resonant output voltage without ripple is stored in battery. Power from the resonant circuit is taken either through a transformer in series with the resonant circuit or series in the capacitor comprising the resonant circuit. In both the cases the high frequency feature of the link allows the use of a high frequency transformer to provide voltage transformation and ohmic isolation between the dc source and the load. The PMDC motor actual motor speed is given to the DSP controller. The controller is maintaining the motor speed as constant with variation of wind voltage.

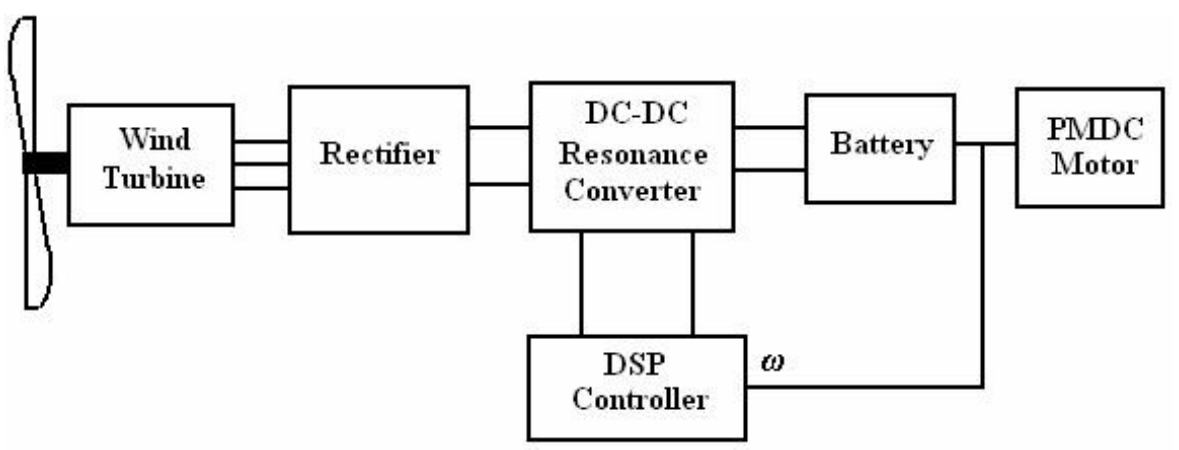

Figure 1. Block diagram of Resonant Converter with DPS controller. 


\subsection{AC Analysis of CLL RC}

The converter is operated only in the lagging power factor mode, AC sinusoidal analysis has been carried out to bring out the important features of the network. Also, in the AC analysis, the output rectifier and filter are replaced by the equivalent AC resistance and the square-wave input voltage source is replaced by its fundamental sinusoidal equivalent. The power transfer from input to output is assumed to be only via the fundamental component and the contribution of all the harmonics is neglected. Without losing generality, the turn's ratio $\left(\mathrm{N}_{1} / \mathrm{N}_{2}\right)$ of the isolation transformer is assumed to be unity. The equivalent AC resistance for the rectifier with capacitive filter and the RMS value of the fundamental component of input square-wave voltage are given by

$$
\begin{aligned}
& V_{\text {iac }}(t)=\sum_{n=1,3,5 . .}^{\alpha} \frac{2 V_{i}}{n \pi} \operatorname{Sinn} \omega_{s} t \\
& R_{a c}=\frac{8}{\pi^{2}} R_{o}
\end{aligned}
$$

The resonant frequency and the normalized switching frequency are defined as

$$
\begin{aligned}
& \omega_{r}=\frac{1}{\sqrt{L C}}, f_{r}=\frac{1}{2 \pi \sqrt{L C}}, \\
& \omega_{n}=\frac{\omega_{s}}{\omega_{r}}, \quad f_{n}=\frac{f_{s}}{f_{r}} .
\end{aligned}
$$

The characteristics impedance and $\mathrm{Q}$ of the resonant network are

$$
Z=\sqrt{\frac{L}{C}} \text { and } Q=\frac{\omega_{r} L}{R_{o}}=\frac{Z}{R_{o}}
$$

The ratio of inductance is defined as

$$
\gamma=\frac{L_{2}}{L_{1}}
$$

The voltage and current gain are defined as

$$
\begin{gathered}
M=\frac{V_{o}}{V_{i n}} \\
H=\frac{I_{o}}{\left(\frac{V_{i n}}{Z}\right)}
\end{gathered}
$$

Voltage gain and current gain for the converter is computed by using equation (5) and (6). Normalized RMS voltage and current ratings of inductor $\mathrm{L}$ are

$$
\frac{V_{L, r m s}}{V_{i}}=\frac{I_{L, r m s}}{\left(V_{i} / Z\right)}
$$

Similarly, normalized voltage and current rating of capacitor $\mathrm{C}$ can be given by

$$
\frac{V_{C, r m s}}{V_{i}}=\frac{I_{C, r m s}}{\left(V_{i} / Z\right)}
$$

Voltage gain and current gain for the CLL RC is obtained using the AC analysis. The AC resonant tank is excited by an effective sinusoidal input source and derives an effective load. The voltage and current gain of SPRC can be derived from equation (5) and (6). The dc voltage source, transformer loss, and load are neglected for the analysis.

By applying the KVL and the equation can be written as (Figure 2)

$$
\begin{gathered}
{\left[\begin{array}{cc}
\frac{1}{C s}+L_{1} s & -L_{1} s \\
-L_{1} s & R_{a c}+\left(L_{1}+L_{2}\right) s
\end{array}\right]\left[\begin{array}{l}
I_{1} \\
I_{2}
\end{array}\right]=\left[\begin{array}{c}
V_{i} \\
0
\end{array}\right]} \\
\Delta=L_{1} s\left[\frac{R_{a c}}{L_{1} C s^{2}}+\frac{1}{C s}+\frac{L_{2}}{L_{1} C s}+R_{a c}+L_{2} s\right]
\end{gathered}
$$




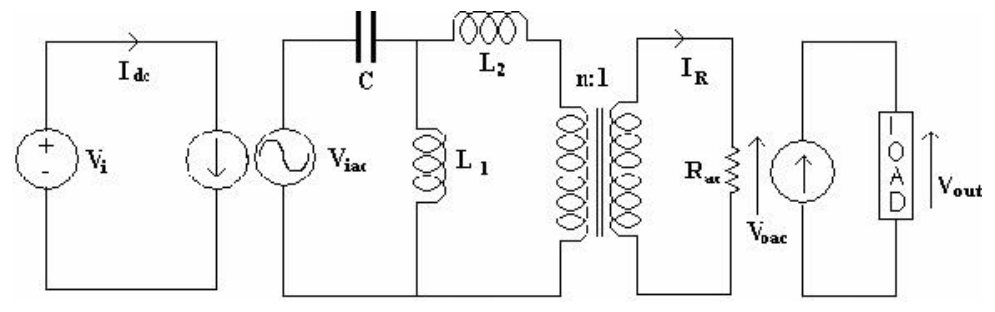

Figure. 2 Circuit diagram of SPRC circuit

By applying KVL in the equivalent circuit and we get the $\mathrm{I}_{2}$

$$
\begin{aligned}
& \Delta I_{2}=V_{i} L_{1} s \\
& I_{2}=\frac{\Delta I_{2}}{\Delta}=\frac{R_{a c}}{\frac{R_{i c}}{L_{1} C s^{2}}+\frac{1}{C s}+\frac{L_{2}}{L_{1} C s}+R_{a c}+L_{2} s}
\end{aligned}
$$

Substituting the equation (2) (3) and (4) in the above equation (8)

$$
\frac{V_{0}}{V_{i}}=\frac{R_{a c}}{R_{a c}\left(1-\frac{1}{\omega_{n}^{2}}\right)+j \frac{R_{L} Q}{\omega_{n}}\left(\gamma \omega-\frac{\omega_{n}^{2}}{\omega}-\frac{\gamma \omega_{n}^{2}}{\omega}\right)}
$$

Simplify the above equation and voltage gain is

$$
M=\frac{V_{o}}{V_{\text {in }}}=\frac{1}{\left(1-\frac{1}{\omega_{n}}\right)+j \frac{\pi^{2}}{8} Q\left(\gamma \omega_{n}-\frac{1}{\omega_{n}}(1+\gamma)\right)}
$$

The current gain is derived from the equation (6) and (9).the current gain for SPRC is

$$
H=\frac{1}{\frac{1}{Q}\left(1-\frac{1}{\omega_{n}}\right)+j \frac{\pi^{2}}{8}\left(\gamma \omega_{n}-\frac{1}{\omega_{n}}(1+\gamma)\right)}
$$

\section{Results and Discussion}

\subsection{Fuzzy Logic Control (FLC)}

Fuzzy control involves three stages: fuzzification, inference or rule evaluation and defuzzification. SPRC is modeled using MATLAB software. Fuzzy control is developed using the fuzzy toolbox. The fuzzy variables 'e', 'ce' and ' u' are described by triangular membership functions. Table I shows the fuzzy rule base created in the present work based on intuitive reasoning and experience. The linguistic labels are divided in to seven groups. These are NH- Negative High, N-Negative, NL- Negative Low, ZZero, PL-Positive Low, P-Positive, PH- Positive High. It can inferred that the output voltage is far from the reference value, then the change of switching frequency ( $\mathrm{u}$ ) must be large so as to bring the output to the reference value quickly. The output voltage approaches the reference value, and then a small change of switching frequency is necessary and if the output voltage is near the

\begin{tabular}{|c|c|c|c|c|c|c|c|c|}
\hline \multicolumn{9}{|c|}{ Error (e) } \\
\hline \multirow{8}{*}{ 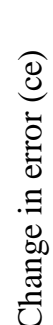 } & & $\mathrm{NH}$ & $\mathrm{N}$ & NS & $\mathrm{Z}$ & PL & $\mathrm{P}$ & $\mathrm{PH}$ \\
\hline & NB & $\mathrm{NH}$ & $\mathrm{NH}$ & $\mathrm{NH}$ & $\mathrm{NH}$ & $\mathrm{N}$ & NL & $\mathrm{Z}$ \\
\hline & $\mathrm{N}$ & $\mathrm{NH}$ & $\mathrm{NH}$ & $\mathrm{N}$ & $\mathrm{N}$ & NL & $\mathrm{Z}$ & PL \\
\hline & NL & $\mathrm{NH}$ & $\mathrm{N}$ & NL & NL & $\mathrm{Z}$ & PL & $\mathrm{P}$ \\
\hline & $\mathrm{Z}$ & $\mathrm{NH}$ & $\mathrm{N}$ & NL & $\mathrm{Z}$ & $\mathrm{PL}$ & $\mathrm{P}$ & $\mathrm{PH}$ \\
\hline & PL & $\mathrm{N}$ & NL & $\mathrm{Z}$ & PL & PL & $\mathrm{P}$ & $\mathrm{PH}$ \\
\hline & $\mathrm{P}$ & $\mathrm{NL}$ & $\mathrm{Z}$ & PL & $\mathrm{P}$ & $\mathrm{P}$ & $\mathrm{PH}$ & PH \\
\hline & $\mathrm{PH}$ & $\mathrm{Z}$ & PL & $\mathrm{P}$ & $\mathrm{PH}$ & $\mathrm{PH}$ & $\mathrm{PH}$ & $\mathrm{PH}$ \\
\hline
\end{tabular}
reference value and is approaching it rapidly, then the frequency must be kept constant so as to prevent overshoot. It is also seen that if the output voltage changes even after reaching the reference value then the change of frequency must be changed by a small amount to prevent the output from moving away.

Table 1. Fuzzy rules 


\subsection{Simulation Results}

The design procedure of the converter was presented (Nagarajan and Madheswaran, 2007; Annamalai and Kumar, 2010; Daniel and Nagarajan, 2018). The closed loop simulation using FLC is carried out using MATLAB/Simulink software. Depending on error and the change in error, the value of change of switching frequency is calculated. The Fuzzy set parameters instruction and function blocks available in MATLAB are used to update the new switching frequency of the pulse generators. The entire system is simulated with a switching frequency of $100 \mathrm{KHz}$. The resonant current and resonant voltage for were estimated and shown in Figure 3. The overshoot and settling time is less and the response is oscillatory. It is clearly shown in that the inverter output as pure square wave without any harmonics and with Resonance frequency.

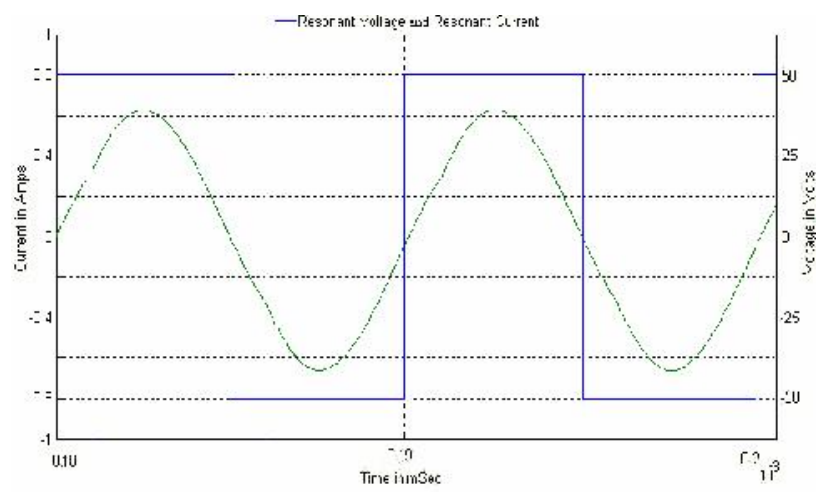

Figure 3. Resonant current and resonant voltage for $\mathrm{V}_{\mathrm{R}}=100 \mathrm{~V}$

It can be seen from this above Figure 3 that the after an initial transient the resonant voltage and resonant current are good accuracy, showing a good tracking performance of the controller. Figure 4 shows the voltage across parallel capacitor waveform at steady state. The Figure 5 shows the inductor current $\mathrm{L}_{1}$ and the current are quite sinusoidal as the converter operates in the resonance frequency. It is almost sinusoidal due to the operating frequency is virtually match with the resonance frequency. In this condition the circuit has a good margin for zero voltage switching operation, providing good response, while the almost sinusoidal current waveform just allows for an extremely low EMI generation.

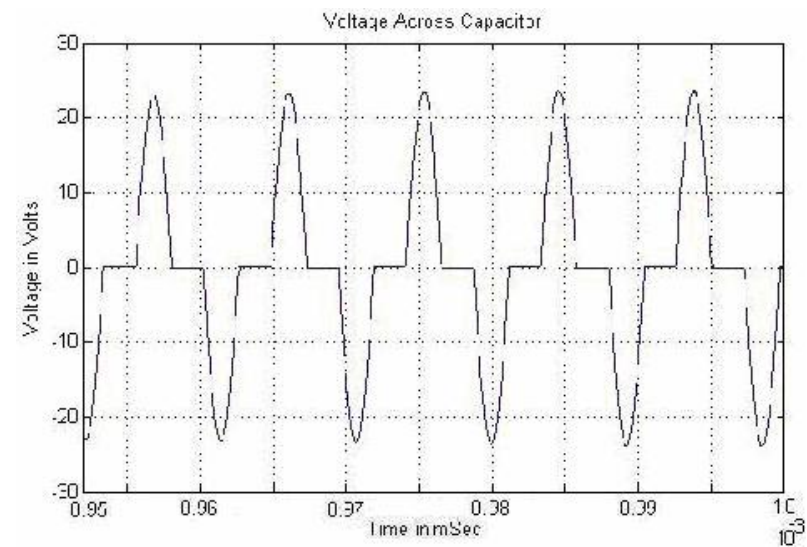

Figure 4. Voltages across parallel capacitor (C)

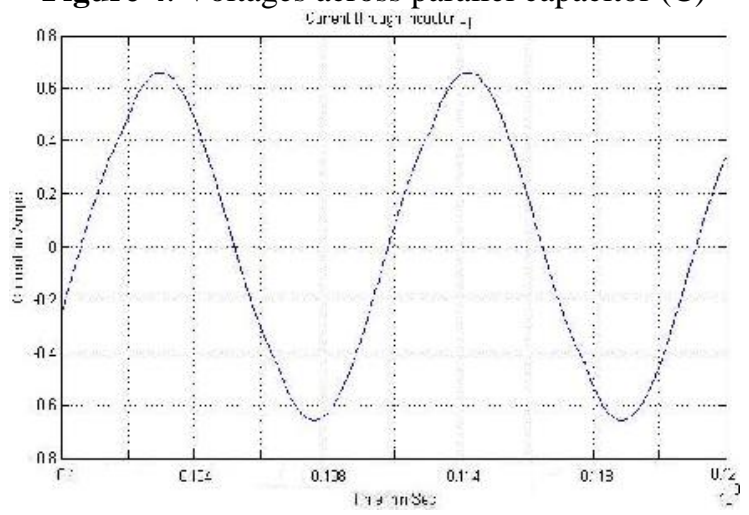


Figure. 5. Current through inductance L

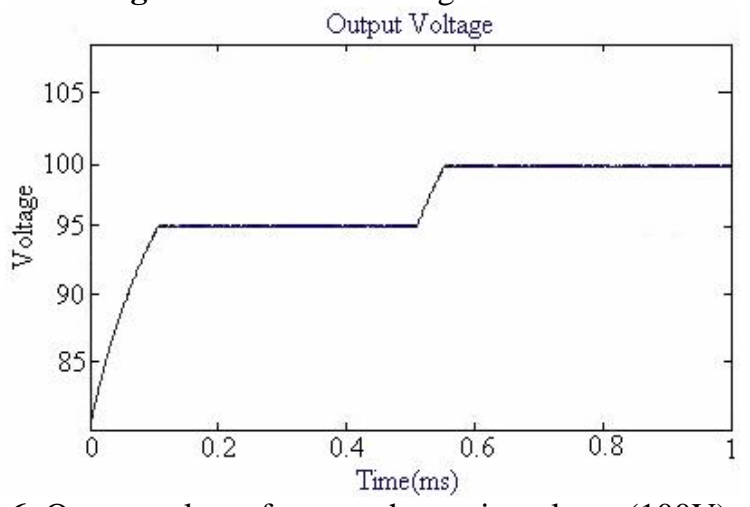

Figure. 6. Output voltage for step change in voltage $(100 \mathrm{~V}), \mathrm{t}=0.5 \mathrm{~ms}$

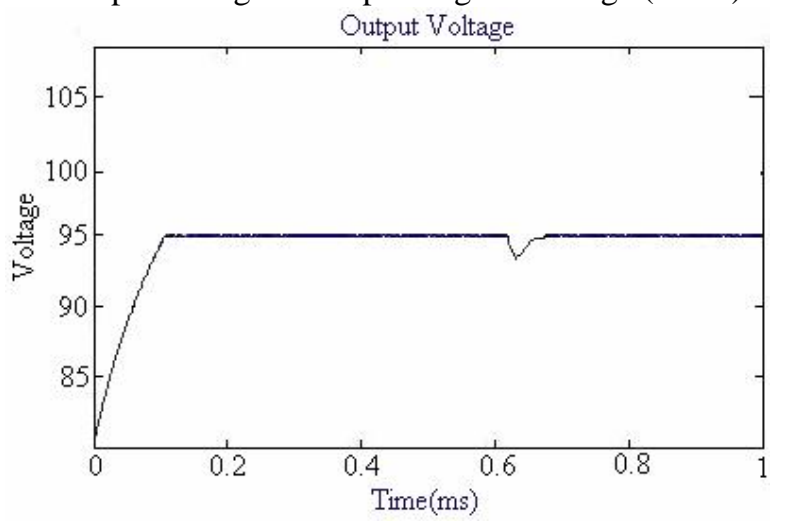

Figure. 7. Output voltage for step change in load. $t=0.6 \mathrm{~ms}$

Figure 6 clearly shows the simulated output voltage with step change voltage from $95 \mathrm{~V}$ to $100 \mathrm{~V}$ at $\mathrm{t}=0.5 \mathrm{mSec}$. The output voltage with load disturbance is shown in Figure 7. The fuzzy logic controller controls the output voltage with less settling time it's nearly $0.02 \mathrm{msec}$. Also the percentage overshoot in output voltage is reduced to $1 \mathrm{~V}$. The result justifies that settling time of output voltage in SPRC very less.

\subsection{AC Analysis}

Figure 8 shows the plots of voltage gain (M) of SPRC as a function of $\omega_{n}$ for $\delta=1$. It is clearly shows the converter control characteristics are achieved for load independent operation and automotive application. This control characteristic is a relationship between the output voltage and switching frequency. Output voltage is a strong function of load over almost entire range of operating frequency. Therefore, a large variation of switching frequency is required to regulate the output voltage against specified input and load changes. It shows that the dependence of output voltage on switching frequency. The load voltage is seen to be independent of load when SPRC is operated at the switching frequency equal to the resonant frequency, that is, at $\omega_{\mathrm{s}}=\omega_{\mathrm{r}}$. As clearly seen from the plot, the control characteristics are closely spaced for lower values of $Q$. Thus, additionally, the output voltage is nearly independent of load over a wide range of switching frequency if a low value of circuit $Q$.

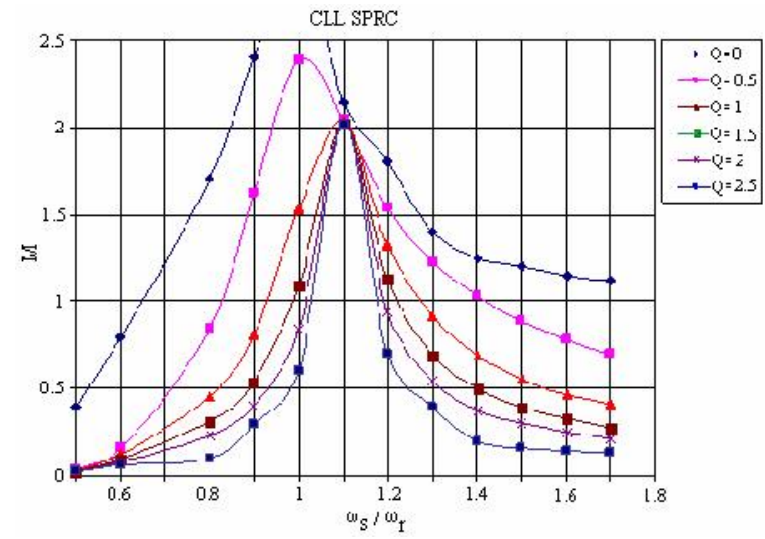

Figure. 8. SPRC control characteristics curves (M Vs $\left.\omega_{\mathrm{s}} / \omega_{\mathrm{r}}\right)$ 


\section{Experimental Results}

A prototype CLL RC is operating at $300 \mathrm{~W}, 100 \mathrm{kHz}$ was designed. The output of the RC tested with change in load and supply. To regulate the output voltage of proposed converter a closed loop control system is designed and implemented. TMS320F2407 Digital Signal Processor is used to generate driving pulses, these pulses are amplified using the driver IC IR2110. The pulses are applied to the gate of the IRF840 MOSFETs through the optocoupler 6N137 and driver IRF 2N2112. The diodes MUR 4100 are used for the output bridge rectifier. The fuzzy controlling program is implemented by this DSP.

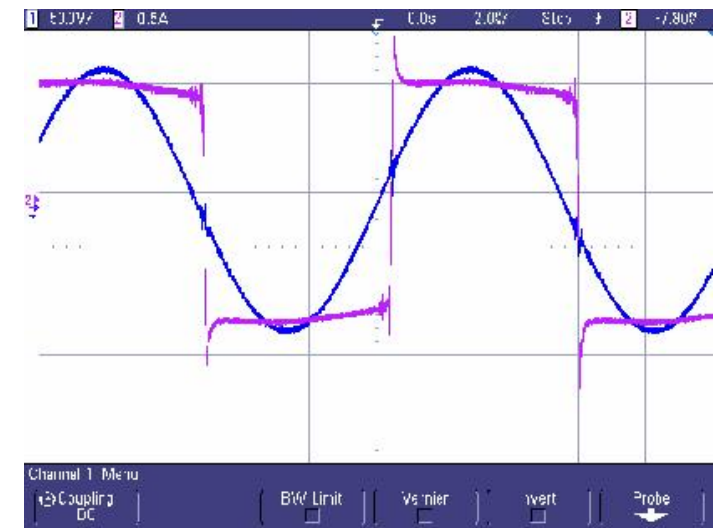

Figure 9. CH1: resonant voltage [volt. scale: 40 V/DIV.].CH2: resonant current [amp. scale: 0.5A/DIV.] for SPRC.

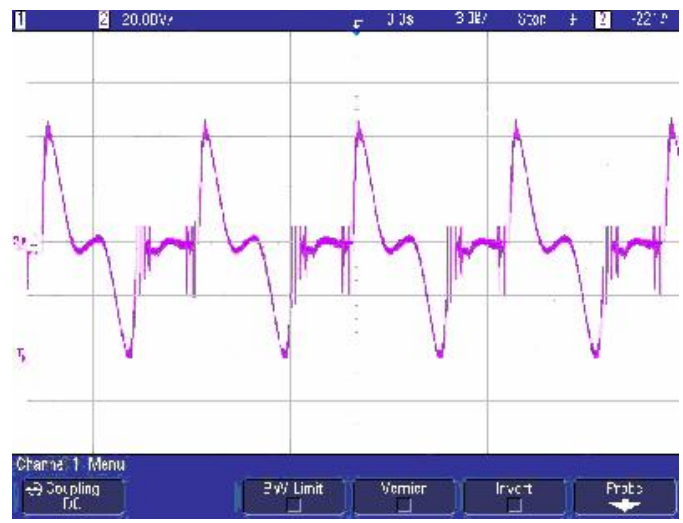

Figure.10.Voltages across capacitor (C) [Volt. Scale: 20 V/div.]

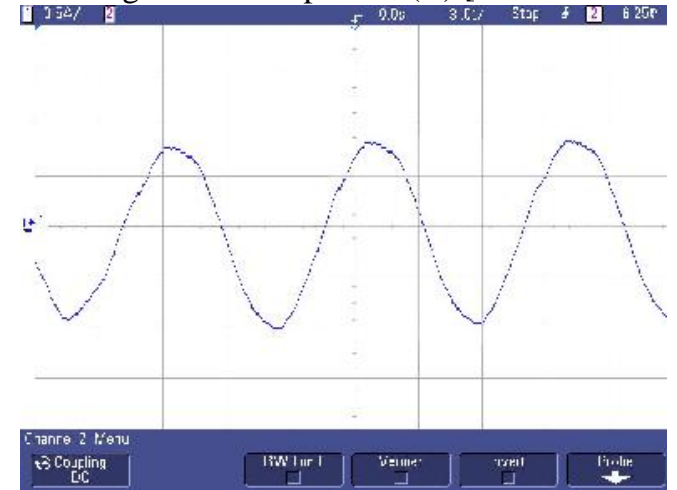

Figure.11.Current through inductance L [Amp. Scale: 0.5A/div.] 


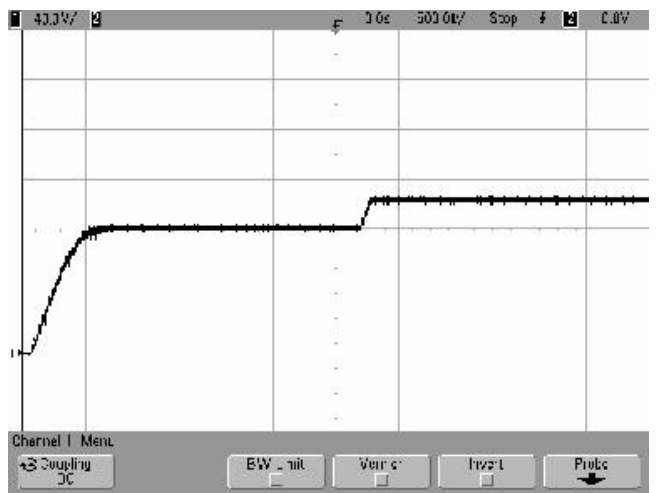

Figure 12. Output voltage for step change in voltage $(100 \mathrm{~V}) . t=0.5 \mathrm{~ms}(\mathrm{CH} 1$ : output capacitor voltage [volt. scale: $40 \mathrm{~V} / \mathrm{DIV}$.]

The above figures show the fuzzy controller output signal for this test. These figures show the good dynamic performance of the controller. Figure 9 shows the resonant voltage, resonant current and output voltage contains harmonic. This harmonics effect is relatively hard for the whole circuit because non-linear loads affect the resonant circuit; it measures from the point A and B of the bridge inverter. Figure 10 shows the capacitor voltage. Figure 11 it can be seen from this figure that the current contains low harmonics and it presents a nearly constant voltage. The controller shows the good performance of the whole design. It can conclude that the controller is capable of operating under load- independent operation, again, it can be seen that the output follows the reference with good accuracy and better dynamic performances. The Figure 12 shows the step change in voltage from $95 \mathrm{~V}$ to $100 \mathrm{~V}$. The settling time is nearly $0.02 \mathrm{~ms}$. The load disturbance is applied in $\mathrm{t}=0.6 \mathrm{~ms}$. The output voltage with load disturbance is shown in Figure 13.

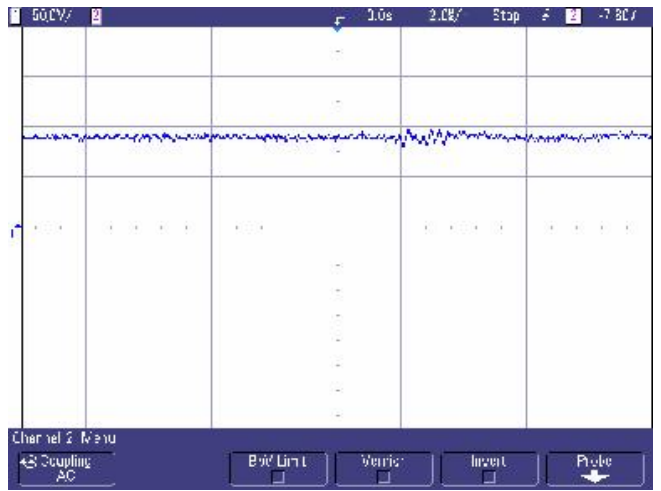

Figure. 13. Output voltage for SPRC with load disturbance at $\mathrm{t}=0.6 \mathrm{~ms}$ (CH1: output capacitor voltage [volt. scale: 50 V/DIV.].

\section{Conclusion}

The CLL RC with DSP base fuzzy controller has been module and simulated for estimating the performance for various load conditions. It has been found from the simulated results that the closed loop controller provides better control strategies. It is concluded that the FLC based CLL RC circuit provide load independent operation and better voltage regulation. A prototype 300 $\mathrm{W}, 100 \mathrm{kHz}$ converter was designed, the experiment results are compared with the simulation results. The simulation results agree with the experimental results. In the future, the performance of converters with neuro fuzzy controller can be extended. Complete study of the topologies (with isolation) with coupled inductors can be considered to reduce the converter size. Design of resonant inductor could be investigated further to reduce the size and improve the efficiency

\section{References}

Annamalai M., Kumar M.V., 2010, Design simulation of CLL resonant DC-to-DC converter for stand alone wind energy system, International Journal of Computer and Electrical Engineering, Vol. 2, No. 5, pp. 875-878. DOI: 10.7763/IJCEE.2010.V2.244

Arulselvi S., Govindarajan U. and Saminath V., 2006, Development of simple fuzzy logic controller (SFLC) for ZVS quasiresonant converter: Design, simulation and experimentation, Journal of the Indian Institute of Science, Vol 86, pp 215-223.

Arun S. and Ramareddy S., 2008, PSPICE simulation and implementation of closed loop controller ZVS LCL push-pull DC-DC Converter, International Journal of Computer Science and Network Security, Vol. 8, No. 6, pp. 67-73. 
Belaguli V., and Bhat A.K.S., 2000, Series-parallel resonant converter operating in discontinuous current mode-analysis, design, simulation, and experimental results, IEEE Transactions on Circuits and System-I: Fundamental Theory and Applications, Vol. 47, No. 4, 433-442. DOI: 10.1109/81.841845

Bhat A.K.S., 1994, Analysis and design of LCL-type series resonant converter, IEEE Transactions on Industrial Electronics, Vol. 41, No. 1, pp. 118 - 124. DOI: 10.1109/41.281617

Borage M., Tiwari S., and Kotaiah S., 2007, LCL-T resonant converter with clamp diodes: A novel constant-current power supply with inherent constant-voltage limit, IEEE Transactions on Industrial Electronics, Vol. 54, No. 2, pp. 741-746. DOI: 10.1109/TIE.2007.892254

Borage M., Tiwari S., and Kotaiah S., 2005, Analysis and design of an LCL-T resonant converter as a constant-current power supply, IEEE Transactions on Industrial Electronics, Vol. 52, No. 6, pp. 1547-1554. DOI: 10.1109/TIE.2005.858729

Correa J.M., Hutto E.D., Farret F.A., Simoes M.G., 2003, A fuzzy-controlled pulse density modulation strategy for a series resonant inverter with wide load range, IEEE Transactions on Power Electronics, Vol. 12, No. 1., pp 1650-1655. DOI: 10.1109/PESC.2003.1217705

Daniel J.P., Nagarajan C., 2018, Hybrid filter for distorted voltage source in microgrids, 2018 Conference on Emerging Devices and Smart Systems (ICEDSS), $2^{\text {nd }}$ and $3^{\text {rd }}$ March 2018, Mahendra Engineering College, Mallasamudram, pp. 11-15.

Foster M.P., Gould C.R., Gilbert A.J., Stone D.A., and Bingham C.M., 2008, Analysis of CLL voltage-output resonant converters using describing function, IEEE Transactions on Power Electronics, Vol. 23, No. 4, pp. 1772-1781. DOI: 10.1109/TPEL.2008.924835.

Geetha E., Nagarajan C., 2018, Induction motor fault detection and classification using current signature analysis technique, 2018 Conference on Emerging Devices and Smart Systems (ICEDSS), $2^{\text {nd }}$ and $3^{\text {rd }}$ March 2018, Mahendra Engineering College, Mallasamudram, pp. 48-52.

Lakshminarasamma N., Masihuzzaman M. and Ramanarayanan V., 2011, Steady-state stability of current-mode active-clamp ZVS DC-DC Converters, IEEE Transactions on Power Electronics, Vol. 26, No. 5, 1295-1304. DOI: 10.1109/TPEL.2009.2022827

Lakshmi C.S. and Nagarajan C., 2017, Multiconverter technology based voltage compensation for photovoltaic system, Ecology, Environment and Conservation, Vol. 23, pp.226-229.

Mattavelli P., Rossetto L., Spiazzi G., Tenti P., 1997, General-purpose fuzzy controller for DC-DC converters, IEEE Transactions on Power Electronics, Vol. 12, No. 1, 79-86. DOI: 10.1109/63.554172

Nagarajan C. and Madheswaran M., 2011, Performance analysis of LCL-T resonant converter with fuzzy/PID using state space analysis, Electrical Engineering, Vol. 93, No. 3, pp.167-178. DOI:10.1007/s00202-011-0203-9

Nagarajan C. and Madheswaran M., 2011, Stability analysis of series parallel resonant converter with fuzzy logic controller using state space techniques, Electric Power Components and Systems, Vol. 39, No. 8, pp.780-793. https://doi.org/10.1080/15325008.2010.541746

Nagarajan C. and Madheswaran M., 2007, Analysis and simulation of LCL series resonant full bridge converter using PWM technique with load independent operation, Presented at ICTES'08, a IEEE / IET International Conference, M.G.R. University, Chennai, Vol. No. 1, pp. 190-195.

Nagarajan C. and Madheswaran M., 2011, Experimental study and comparative analysis of CLL-T and LCL-T series parallel resonant converter with Fuzzy/ PID Controller, Journal of Electrical Engineering, Vol. 11, No. 3, pp.122-129.

Nagarajan C., Madheswaran M. and Ramasubramanian D., 2013, Development of DSP based robust control method for general resonant converter topologies using transfer function model, Acta Electrotechnica et Informatica Journal, Vol. 13, 2, pp.18-31.

Raju G.S.N. and Doradla S., 1995, An LCL resonant converter with PWM control analysis, simulation, and implementation, IEEE Transactions on Power Electronics, Vol. 10, No.2, pp. 164 - 174. DOI: 10.1109/63.372601

Sivakumaran T.S., Natarajan S.P., 2006, Development of fuzzy control of series-parallel loaded resonant converter-simulation and experimental evaluation, 2006 Proceedings of India International Conference on Power Electronics, pp 360-366, 19-21 Dec. 2006, Chennai, India. DOI: 10.1109/IICPE.2006.4685398

Udhayakumar K., Lakshmi P., Boobal K., 2008, Hybrid posicast controller for a DC-DC buck converter, Serbian Journal of Electrical Engineering, Vol. 5, No. 1, pp.121-138.

\section{Biographical notes}

C. Nagarajan and R. Prakash are of the Centre for Advanced Research, Department of Electrical and Electronics Engineering, Muthayammal Engineering College, Salem, Tamilnadu, India 